\title{
DIE MUSIK IN DER ST. NIKOLAUSKIRCHE AUF DER PRAGER KLEINSEITE IN DER ERSTEN HÄLFTE DES 18. JAHRHUNDERTS
}

Zu Beginn meines Beitrages möchte ich gerne Jiř́ Sehnal paraphrasieren, der in der letzten synthetischen Arbeit über die Musik in den böhmischen Ländern das Prag der ersten Hälfte des 18. Jahrhuderts als ,tatsächliche Großmacht der Kirchenmusik" bezeichnete. ${ }^{1}$ Die Prager Konurbation zeichnete sich durch eine ungewöhnliche Konzentration an bedeutenden Kirchen und Klöstern aus, von denen einige sogar die Zentrale des Ordens (wie es beispielsweise bei den Kreuzherren mit dem roten Stern der Fall war) oder die Ordensprovinz (zum Beispiel Jesuiten oder Prämonstratenser) darstellten. Mit ein wenig Übertreibung kann man sagen, dass einzelne Häuser gerade im Bereich der Figuralmusik einen gegenseitigen Konkurrenzkampf betrieben. Als die Zeit des größten Aufschwungs kann in etwa das erste Drittel des 18. Jahrhunderts genannt werden, eine Zeit, als sich die Prager Städte auch ein barockes Gewand zulegten. Demgegenüber ist es in einigen etwas später errichteten Klöstern vor allem in der Neustadt schon nicht mehr zu einer größeren Blüte des Musikbetriebs gekommen. ${ }^{2}$

* Die Studie entstand im Rahmen des Postdoktorat-Projekts der GAČR P409/12/P953 The Composer and His Work in the Baroque Prague: Johann Joseph Ignaz Brentner (1689-1742).

1 SEHNAL, Jiří. Pobělohorská doba (1620-1740) [Die Zeit nach dem Weißen Berg]. In ČERNÝ, Jaromír u.a. Hudba v českých dějinách: od středověku do nové doby. 2. Ed. Praha: Supraphon, 1989, S. 147-215, hier S. 173 und 215. Prag als ein musikalisches Zentrum zu Beginn des 18. Jahrhunderts behandelte VOLEK, Tomislav. Die Bedeutung Prags für Zelenkas Leben und Schaffen. In Zelenka-Studien I (Musik des Ostens 14). Kassel: Bärenreiter, 1993, S. 17-40. Als Standardwerk über das Prager Musikleben der damaligen Zeit gilt bis heute das Buch von KAMPER, Otakar. Hudebni Praha v XVIII. věku [Das musikalische Prag im 18. Jahrhundert]. Praha: Melantrich, 1936, siehe auch HELFERT, Vladimír. Jiři Benda: př́spěvek $k$ problému české hudebni emigrace $=$ Georg Benda: Zum Problem der böhmischen Musikemigration. Bd. I. Brno: Filosofická fakulta s podporou Ministerstva školství a národní osvěty, 1929, S. 47-56.

2 SLAVICKÝ, Tomáš. Hudební život klášterů Nového Města pražského v letech 1680-1780 [Das Musikleben der Klöster der Prager Neustadt 1680-1780]. In Locus pietatis et vitae. Praha: UK - Scriptorium, 2008, S. 481-506. 
Fragen wir nun jedoch nach den Quellen, sieht die musikalische Landkarte Prags in der ersten Hälfte des 18. Jahrhunderts anders aus: Lediglich zwei größere Musikaliensammlungen sind in relativer Gänze erhalten geblieben, und zwar die der Kreuzherren- und der Dommusikarchive. ${ }^{3}$ Im Falle von zwei weiteren aus der zweiten Hälfte des 18. Jahrhunderts stammenden Musiksammlungen stehen zumindest die Reste älterer Musikalien zur Verfügung - wie es für Strahov der Fall ist - oder es ist dazu ein älteres Musikinventar vorhanden wie im Falle der Loreto-Kirche auf dem Hradschin. ${ }^{4}$ Einzelne, aus der ersten Hälfte des 18. Jahrhunderts stammende Quellen sind natürlich auch in weiteren Prager Sammlungen aus späterer Zeit erhalten geblieben, und in beiden zuerst genannten großen Sammlungen befinden sich zweifellos auch Quellen, die aus anderen Prager Chören stammen. ${ }^{5}$ Dennoch stehen heute nur wenig konkrete Informationen über die Musik in einer ganzen Reihe bedeutender Prager Kirchen zur Verfügung - und das gilt nicht nur für die heute nicht mehr existierenden. ${ }^{6}$

Einen spürbaren Verlust stellt vor allem das Fehlen von Musikalien aus Prager Jesuitenkirchen dar. Weder Musik noch die Musikinventare sind von den Altstädter und Neustädter Jesuiten erhalten geblieben: zu den absolut vereinzelten Torsi gehört beispielsweise die einzigartige Quelle von Vivaldis Dixit Dominus RV 595, die aus dem Neustädter Jesuitenseminar stammt oder auch die Kompositionen von Jan Dismas Zelenka, die er für das Prager Klementinum schrieb (ZWV 58-60). Ansonsten sind wir im Falle der beiden erwähnten Prager Jesuitenhäuser auf nichtmusikalische Quellen angewiesen, also einzeln erhalten gebliebene Libretti von Oratorien oder schriftliche Quellen wie Diaria, Jahresberichte oder Rechnungen, die allerdings in ihrer Beziehung zum Musikbetrieb bisher nicht flächendeckend untersucht wurden. ${ }^{7}$ Darüber hinaus gilt, dass im Falle von jesuiti-

3 Die Musiksammlung der Prager Kreuzherren mit dem Roten Stern (CZ-Pkřiž) ist unter der Verwaltung des Ordens. Ein bedeutender Teil der Sammlung ist in RISM verarbeitet. Zur Dommusiksammlung (CZ Pak) siehe PODLAHA, Antonín. Catalogus collectionis operum artis musicae quae bibliotheca capituli metropolitani pragensis asservantur (Editiones Archivii et Bibliothecae S.F. Metropolitani capituli pragensia XIX). Pragae: Sumptibus S.F. Metropolitani capituli prag., 1926. ŠTEFAN, Jiří. Ecclesia metropolitana Pragensis catalogus collectionis operum artis musicae. 2 Bd. Praha: Supraphon, 1983-1985.

PULKERT, Oldřich. Domus Lauretana Pragensis: Catalogus collectionis operum artis musicae. Pars 1, Catalogus. Praha: Supraphon, 1973, S. 41-60.

5 Siehe zum Beispiel NIUBO, Marc. Auf den Spuren der Musikaliensammlung der Teynkirche. Ein Beitrag zur Musikgeschichte der Kirche St. Maria vor dem Teyn im 17. und 18. Jahrhundert. In ČERNÝ, Jaromír - KOCH, Klaus-Peter, eds. Mitteleuropäische Aspekte des Orgelbaus und der geistlichen Musik in Prag und den böhmischen Ländern: Konferenzbericht Prag, 17.-22. September 2000. Sinzig: Studio, 2002, S. 289-297.

6 Ausgewählten Aspekten der Musik in heute nicht mehr existierenden Prager Kirchen widmete sich sie die bemerkenswerte Ausstellung des Nationalmuseums - Tschechisches Musikmuseum, die vom 5. 10. 2007-4. 2. 2008 stattfand, vgl. die Publikation Zaniklé chrámy: živá hudba $=$ Extinct churches: living music. Praha: Národní muzeum, 2007.

7 Zu den gedruckten Libretti von im Klementinum aufgeführten Oster-Oratorien vgl. BUŽGA, Jaroslav. Einige Quellen zur Geschichte der Osteroratorien in Prag und Brno (Brünn) und der Ostermelodramen aus Olomouc (Olmütz) im 18. Jahrhundert. In De musica disputationes 
schen Häusern mit einer langen Tradition und konstantem Betrieb Erwähnungen von konkreten musikalischen Ereignissen in ähnlichen Quellen sehr viel weniger oft zu finden sind als im Falle von neu gegründeten Häusern oder Missionen; höchstwahrscheinlich kann man also nicht davon ausgehen, dass eine solche Untersuchung ebenso produktiv wäre wie beispielsweise Exzerpte von musikalischen Erwähnungen aus den Diaria der Dresdener Jesuitenmission. ${ }^{8}$

Lediglich aus der Kleinseitner Jesuitenkirche St. Nikolaus sind Musikalien sowie ausführlichere Quellenberichte zum Musikbetrieb in größeren Mengen erhalten geblieben. Es handelt sich vor allem um ein Torso der Musiksammlung, das zu den wertvollsten Teilen der Sammlung von Ondřej Horník im National Museum - Tschechisches Musikmuseum (CZ Pnm) gehört und die unter anderem Musikalien aus der Jesuitenzeit enthält. ${ }^{9}$ Und obwohl der überwiegende Teil erst aus der zweiten Hälfte des 18. Jahrhunderts stammt, sind dort ältere Musikalien in einem solchen Maße vertreten, dass es sich zweifellos um die drittbedeutendste Musiksammlung Prager Provenienz für die erste Hälfte des 18. Jahrhunderts handelt. Die Musikalien aus der St.-Nikolaus-Kirche sind darüber hinaus auch in weiteren Fonds des Tschechischen Musikmuseums und in der Nationalbibliothek $(\mathrm{CZ} \mathrm{Pu})$ präsent, was bisher nicht zusammenfassend reflektiert wurde. Neben Musikalien sind auch Akten erhalten geblieben, die im direkten Zusammenhang

Pragenses. Prag: Academia Verl. der Tschechoslowakischen Akademie der Wissenschaften, 1972, S. 151-171 und POŠTOLKA, Milan. Libreta strahovské hudební sbírky / Die Libretti der Strahover Musiksammlung. Miscellanea musicologica 25-26, 1973, S. 79-149. Jesuitische Diaria, Jahresberichte und andere Schriftdokumente wurden in Bezug auf Musik bisher nicht im vollen Umfang genutzt. Eingehendere Aufmerksamkeit wurde diesen Dokumenten lediglich im Zusammenhang mit Jan Dismas Zelenka und der Dresdener Jesuitenmission gewidmet, vgl. Zelenka-Studien I (Musik des Ostens 14). Kassel: Bärenreiter, 1993 und STOCKIGT, Janice B. The Vespers psalms of Jan Dismas Zelenka (1679-1745) in the liturgy and life of the Dresden Catholic court church. Melbourne: University of Melbourne, 1994. Das Forschungsinteresse galt hingegen den Musik-Präfekten aus den Reihen des Jesuitenordens, vgl. HOLUBOVÁ, Markéta. Biografický slovnik hudebnich prefekti̊ jezuitského ř́du působicich v Čechách, na Moravě a ve Slezsku v letech 1556-1773 / Biographical dictionary of musical prefects of the Jesuit order active in Bohemia, Moravia and Silesia in the years 1556-1773. Praha: Etnologický ústav Akademie věd České republiky, 2009. Eine synthetische Untersuchung der schlesischen Jesuitenkollegs ist in vielerlei Hinsicht von Wert und verfügt auch in Bezug auf die Prager Jesuitenhäuser über Aussagekraft: JEŻ, Tomasz. Kultura muzyczna jezuitów na Śląsku i ziemi kłodzkiej (1581-1776) [Die Musikkultur der Jesuiten in Schlesien und im Glatzer Land]. Warszawa: Sub Lupa, 2013.

Zelenka-Studien 2: Referate und Materialien der 2. Internationalen Fachkonferenz Jan Dismas Zelenka (Dresden und Prag 1995). St. Augustin: Academia Verlag, 1997, S. 29-41, 43-57, 315-318.

9 ŠTeFANCOVÁ, Dagmar, KABElKOVÁ, Markéta, PAUlOVÁ, Eva. Hudební sbirka Ondřeje Horníka. I. díl, Sbirka hudebnin, knihovna a výtvarné dokumenty [Ondřej Horníks Musiksammlung. I. Teil, Musikaliensammlung, Bibliothek und Kunstdokumente]. Praha: Národní muzeum, 2012. (Editio Monographica Musei Nationalis Pragae, 14/1). Die Sammmlung wurde schon teilweise elektronisch katalogisiert, http://opac.nm.cz:8080/opaccmh/ [zit. 1. 4. 2014]. 
mit der Musik in dieser Kirche für den untersuchten Zeitraum zusammenhängen. ${ }^{10}$ Und schließlich fällt die Einweihung des ambitiösen Kirchenbaus mit dem Beginn eines starken Zustroms italienischen Repertoires nach Prag zusammen, und so wurde diese Kirche naturgemäß zu einem Ort, wo diese Musik aufgeführt wurde; eine Tatsache, die auch in den jesuitischen Quellen, die in solchen Dingen ansonsten eher weniger Informationsgehalt bieten, reflektiert wurde.

Die Verarbeitung und gründliche Auswertung aller dieser Quellen ist eine Aufgabe, die erst in Angriff genommen werden muss und die die Möglichkeiten dieses Beitrages weit übersteigt. Die Ziele meiner Studie sind sehr viel bescheidener. Ich habe lediglich die Absicht, verschiedene Richtungen anzudeuten, in die sich die Forschung zu den mit der St.-Nikolaus-Kirche in Zusammenhang stehenden Musikquellen bewegen könnte, und zwar am Beispiel konkreter Fragen, die mit einigen der betreffenden Musikquellen in Verbindung stehen. Gleichzeitig möchte ich jedoch auch eine sich anbietende Parallelität aufgreifen, nämlich die Parallelität zwischen der fulminanten, radikalen Barockarchitektur der neuen Kirche, die im Verlauf der ersten Hälfte des 18. Jahrhunderts das Gesicht der Stadt veränderte, und der nicht minder bedeutenden Stellung, die die Musik bei den Kleinseitner Jesuiten innerhalb der Prager musikalischen Landschaft jener Zeit einnahm.

$$
* * *
$$

Die zuerst katholische und danach utraquistische gotische St.-Nikolaus-Kirche war die Hauptpfarrkirche der Prager Kleinseite. Die Jesuiten übernahmen die Verwaltung der Kirche nach der Schlacht auf dem Weißen Berg und konnten mit Unterstützung von Albrecht von Waldstein auch die Nachbargebäude übernehmen. 1626 wurde bei der Kirche ein Professhaus gegründet, später kam noch ein Gymnasium hinzu. ${ }^{11}$ Die Pfarrei wurde damals auf die benachbarte St.-WenzelsKirche übertragen, die in diesem Zusammenhang ausgebaut wurde. Zu der Zeit hatten die Jesuiten allerlei Verhandlungen und Streitigkeiten mit der Stadt und der benachbarten St.-Thomas-Pfarrei, wohin für einige Zeit auch die Agenda der St.-Nikolaus-/St.-Wenzels-Pfarrei verlegt wurde. ${ }^{12} 1673$ begann dann schließlich ein umfangreicher barocker Ausbau, der die urbanistische Gestalt des Kleinseit-

10 NETTL, Paul. Akten zur Geschichte und Organisation der Prager Kirchenmusik im 18. Jahrhundert. Mitteilungen des Vereines für Geschichte der Deutschen in Böhmen 67, 1029, Hf. 3-4, S. 114-125.

11 Mit der Geschichte des jesuitischen Professhauses hat sich PODLAHA, Antonín beschäftigt. Dějiny kolejí jesuitských v Čechách a na Moravě od $r .1654$ až do jejich zrušení. Část první, Od roku 1654 do 1723. [Die Geschichte der Jesuitenkollegs in Böhmen und Mähren von 1654 bis zu ihrer Auflösung. Erster Teil, Von 1654 bis 1723.] Praha 1914. Vgl. auch BUBEN, Milan M. Encyklopedie řádů, kongregací a řeholních společností katolické církve v českých zemich. III. díl, 4. svazek: Řeholni klerikové (jezuité) [Enzyklopädie der Orden, Kongregationen und Ordensgesellschaften der katholischen Kirche in den böhmischen Ländern. II. Teil, 4. Band: Ordenskleriker (Jesuiten)]. Praha: Libri, 2012, S. 334-343.

12 Einzelne Akten dazu im Archiv Hlavního města Prahy [Archiv der Hauptstadt Prag, im Folgenden AMP], FÚ u sv. Mikuláše na Malé Straně [Bestand der Pfarrgemeinde von St. Nikolas auf der Kleinseite], i. č. 66, kart. 3. 
ner Platzes gänzlich verändern sollte; den Grundstein legte Kaiser Leopold I., und es sind auch kleinere Erwähnungen in Bezug auf die Musik bekannt, die bei diesem feierlichen Anlass gespielt wurde. ${ }^{13}$ Zunächst wurde das neue Professhaus errichtet, in das die völlig neue St.-Wenzels-Pfarrkirche integriert wurde. Gleichzeitig wurden die Fundamente für die Frontseite der neuen St.-Nikolaus-Kirche gelegt, die entscheidende Phase des Ausbaus fand jedoch erst im neuen Jahrhundert statt. 1711 wurde ein Teil der neuen Kirche provisorisch überdacht und von Mauern umschlossen, damit Gottesdienste darin stattfinden konnten. 1713 wurde die Totenkapelle fertig gestellt sowie die Portaltreppe errichtet, 1721 der Fußboden gelegt. Zu der Zeit stand immer noch die alte mittelalterliche Kirche, deren Reste erst 1743 beseitigt wurden. Das Kreuzschiff, die Kuppel und der Glockenturm der neuen Kirche wurden dann bis 1752 fertig gestellt. ${ }^{14}$

Als Sitz der Ordenselite, die von den patres professi quattuor votorum gebildet wurde, hatte das domus professae in der Hierarchie der Ordenshäuser eine Ausnahmestellung inne. Laut Ordensstatuten durfte das Professhaus kein Eigentum besitzen, keine dauerhaften Einkünfte aus Stiftungen haben und auch über keine Schule verfügen. Am Kleinseitner Professhaus wurde zwar auf Forderung der Stadt ausnahmsweise ein Gymnasium errichtet, Träger war allerdings das Klementinum und die Mittel für den Betrieb kamen von der Stadt. ${ }^{15}$ Das Stiftungsverbot bezog sich auch nicht auf die Kirchenmusik. ${ }^{16}$ Eine erste Stiftung wurde zu diesem Zweck 1631 von Graf Adam Jiř́ Kokořowecz z Kokořowa gegründet, sie war bestimmt ,, na pomocy $k$ wichovani spievakuv a mladenizuw kterýžby již $v$ znamowanym kostele u Svateho Mikulase Msse Svate a Nesspory muzikau ozdobovaly, a Pana Boha chwalily“ “(,zur Hilfe bei der Erziehung der Sänger und junger Menschen, die in der genannten Kirche zum Heiligen Nikolaus die Heiligen Messen und Vespern mit Musik schmücken und den Herrgott preisen werden"). Es handelte sich allerding um die Übertragung von Verpflichtungen, die die Stadt Saaz (Žatec) gegenüber dem Grafen Kokořowecz hatte, und es scheint, dass die Jesuiten bei der Einforderung der Zahlungen Probleme hatten, sodass die Stiftung 1683 schließlich aufgelöst wurde. ${ }^{17}$ Eine weitere Stiftung für Musik und Musiker in der St.-Nikolaus-Kirche gründete 1657 Graf Adam Matthias Trauttmansdorff. ${ }^{18}$

13 PODLAHA, Dějiny, S. 71.

14 Zur Baugeschichte der Kirche siehe VLČEK, Pavel u.a., Umělecké památky Prahy. Malá Strana [Prager Kunstdenkmäler, Kleinseite]. Praha 1999, S. 91-100. Siehe auch MUCHKA, Ivan. St.-Nikolauskirche auf der Prager Kleinseite. Regensburg: Schnell \& Steiner, 1995 und BAŽANT, Jan - BAŽANTOVÁ, Nina. Svatý Mikuláš na Malé Straně: největši barokní chrám v Praze [St. Nikolaus auf der Kleinseite: Die größte Prager Barockkirche]. Praha: Festina Lente Press, 2011.

15 BOBKOVÁ-VALENTOVÁ, Kateřina. Každodenní život učitele a žáka jezuitského gymnázia [Der Alltag von Lehrern und Schülern des Jesuiten-Gymnasiums]. Praha: Karolinum, 2006, S. 11; PODLAHA, Dějiny, S. 83. Vgl. JEŻ, op. cit., S. 385.

17 Národní archiv [Nationalarchiv, weiter NA], Bestand Jesuitica (JS), Kart. 10, Mappe II/2/11. PODLAHA, Déjiny, S. 77. 
Die Musikpflege war schließlich auch ein Bestandteil der Stiftung von Gräfin Lucia Otilia von Kolowrat für Coetus Defunctorum, eine Totenbruderschaft, die 1693 mit der Bruderschaft der Todesangst Christi (Coetus Agoniae) zur Congregatio Christi in cruce agonizantis et mortui vereinigt wurde (zu einigen Musikquellen, die mit dieser Bruderschaft zusammenhängen, siehe weiter unten). ${ }^{19}$

Konkrete Informationen über den Musikbetrieb in der alten Kirche sind nicht bekannt. Die älteste Schicht der erhalten gebliebenen Musikalien der St.-Nikolaus-Sammlung stellen allerdings Quellen vom Beginn des 18. Jahrhunderts dar, das bedeutet, dass es sich zweifellos um Musik handelt, die noch in der alten Kirche erklang. Einige dieser wertvollen Einzelstücke wie die Vesperae von Johann Christoph Pez oder das Dixit Dominus von Ruggiero(?) Fedeli lassen die Existenz von bisher nicht näher bekannten Repertoireverbindungen zu Höfen oder Ordenshäusern in Deutschland erahnen. ${ }^{20}$ Ein anderes Mal handelt es sich um eine feierliche Komposition für ein bedeutendes Ereignis, welches zweifellos der Namenstag des Hl. Ignatius darstellte (das zweichörige Mottetum de S. Patre Ignatio, eine der ältesten bekannten Kompositionen von Wenzel Gunther Jacob von 1708). ${ }^{21}$ Des Weiteren gehören hierzu zwei Kompositionen des Jesuiten Wenzel Majer, der 1705 als Praefectus musicae im Kleinseitner Professhaus tätig war. Wie aus den Angaben auf den für die ältesten St.-Nikolaus-Musikalien typischen, mit schwarzer Tinte geschriebenen Umschlägen hervorgeht, stammen die Abschriften aus den Jahren 1707 und 1708. ${ }^{22}$ Und schließlich war vielleich für die regelmäßigen Totenmessen der erwähnten Coetus Franz Rumpelnigs Requiem aus dem Jahr 1709 bestimmt, das aufgrund der dunklen Instrumentalbesetzung, die lediglich aus Violas besteht, besonders bemerkenswert ist. Diese Komposition eines heute nahezu unbekannten Komponisten, der als Kapellmeister der Esterházyschen Hofmusik in den Jahren 1702-1714 belegt ist, war in Prag offenbar beliebt, da sie in späteren Abschriften auch an anderen Prager Chören erhalten geblieben ist. ${ }^{23}$ Die Anmerkung ,revisum F. Novak“ auf den St.-Nikolaus-

19 PODLAHA, Dějiny, S. 87-88; MILLER, Joannes. Historia provinciae bohemiae Societatis Jesu ab Anno Domini 1555 ... ad annum 1723. Liber V et VI, S. $1873 \mathrm{ff} . \mathrm{CZ}$ Pu, Sign. XXIII.C.104/3, Erhältlich online: http://www.manuscriptorium.com/ [zit. 1. 4. 2014]

20 CZ Pnm, Sign. XIII F 52: „Vesperae | de Beatissima Virgine | A. 10. | Cant: Alt: Ten. Basso | Violinis 2. | Clarinis 2. |Violis 2. | Con Organo | Authore Don Christophoro Pez" und daselbst, Sign. IX A 104: „Dixit Dominus | A 4. | Canto, Alto, Tenore, Basso, | 2. Violin: 3 Tromb: 2. Organo | Authore Virtuoso D[omi]no Fedeli | Choro S: Nicol: Soc: Jesu donatum | à R. P: R: Soc: Jesu A[nn]o | 1704 | Chartae 11."Einige der ältesten Stimmen dieser beiden Quellen wurden offenbar vom gleichen Kopisten geschrieben.

21 CZ Pnm, Sign. X F 121.

22 Es handelt sich um das zweichörige Dixit Dominus, Sign. XII B 136, und das Offertorium O Panis caelice, Sign. XII B 137. Zur Ordenskarriere des Komponisten siehe HOLUBOVÁ, op. cit., Nr. 358, S. 90-91.

23 CZ Pnm, Sign. XIV F 39. Die Kirchenkompositionen Franz Rumpelnigs einschließlich des genannten Requiem sind u.a. in CZ Pkřiž und CZ Pak enthalten, seine Instrumentalmusik befindet sich in Wiesentheid, siehe RISM (unter Rumpelnig und Rumpeling) und ZOBELEY, Fritz. Die Musikalien der Grafen von Schönborn-Wiesentheid: Thematisch-bibliogra- 
Stimmen deuten das Engagement des späteren St.-Veits-Kapellmeisters auch am St.-Nikolaus-Chor an.

$$
* * *
$$

Im darauffolgenden Jahrzehnt bestimmte die neue Kirche die Prager Musiklandschaft in gleicher Intensität wie das ungewöhnlich dynamisch geschwungene Portal das Stadtbild der Prager Kleinseite. Unmittelbar nach der Verlegung der Gottesdienste aus der alten Kirche, was unter großer Anteilnahme zu Allerheiligen 1711 geschah, gelangte die neue Kirche ins Augenmerk der musikliebenden Prager Gesellschaft. Die jesuitischen Litterae annuae beschreiben in jenem Jahr nicht nur ausführlich die neue Kirche, sondern beinhalten auch eine kurze Bemerkung darüber, dass die ausgewählte Musik vom adligen Herrn Hartig besorgt wurde; dabei ist aber nicht klar, ob es sich hierbei um die Musik handelte, die die Feierlichkeiten im Zusammenhang mit der Verlegung der Gottesdienste begleitete. Angesichts des überwiegend allgemeinen und zusammenfassenden Charakters der Quelle hat diese Bemerkung jedoch ein gewisses Gewicht. ${ }^{24}$ Der Eintrag des Folgejahres lässt allerdings keinen Zweifel daran, dass es sich um Johann Hubert Hartig handelte, der diesmal mit ganzem Namen einschließlich seiner Funktion des Statthalters erwähnt wird. Informiert wird auch darüber, dass er für die Musik im Rahmen des Titularfestes der neuen Kirche zuständig war. ${ }^{25}$ Es sei daran erinnert, dass dieser Mann in jener Zeit (in den Jahren 1709, 1712, 1716) bei seinem Schützling Jan Dismas Zelenka auch die Karfreitagsmusik für das Heilige Grab des Klementinums bestellte, und mit großer Wahrscheinlichkeit war es auch dieser Angehöriger der Familie Hartig, der 1713 als bekannter Musikkenner von den Prager Bürgern zum Protektor der sogenannten Musikalischen Akademie gewählt wurde. ${ }^{26}$ Auch wenn in den Litterae annuae keine Kompositionen aufgeführt sind, die Hartig für die St.-Nikolaus-Kirche besorgt hatte, sind die Informationen über sein wiederholtes Engagement in dieser Sache nicht nur ein weiterer Beitrag zur Erhellung seiner bemerkenswerten musikalischen Aktivitäten, sondern werfen auch ein neues Licht auf die Problematik der Prager Oratorien. ${ }^{27}$

phischer Katalog, I. Teil: Das Repertoire des Grafen Rugolf Franz Erwein von Schönborn (1677-1754). Bd. 2: Handschriften, DANGEL-HOFMANN, Frohmut (ed.), Tutzing 1982. Zu seiner Position in Eisenstadt siehe TANK, Ulrich. Studien zur Esterházyschen Hofmusik von etwa 1620 bis 1790. Regensburg: G. Bosse, 1981, bes. S. 56-57.

Archivum Romanum Societatis Iesu (ARSI), Supplementum Historiae 1711[-1713], Boh. 124, p. 1: „Musicam exquisitam instituente Illustrissimo ab Hartig.“

ARSI, Litterae annuae 1712, Boh. 125, p. 8: „Festivitatem Divi Nicolai celeberrimam reddidit exquisita Musica Illustrissimus D. Joannes Liber Baro ab Harttig Locumtenens Regius. “

Letzte Zusammenfassung mit Verweisen auf ältere Literatur vgl. KAPSA, Václav - PERUTKOVÁ, Jana - SPÁČILOVÁ, Jana. Some remarks on the relationship of Bohemian aristocracy to Italian music at the time of Pergolesi. In Studi pergolesiani - Pergolesi studies 8. Bern, Peter Lang, 2012, S. 313-341, hier 317-321. aktuell VEVERKA, Karel. Hudební mecenát hraběte Jana Huberta Hartiga u pražských Křižovníků s červenou hvězdou ve světle řádového listinného archivu [Das Musikmäzena- 
Die ersten Oratorien erklangen in Prag im letzten Drittel des 17. Jahrhunderts, dabei ging es um Werke, die während des Prager Aufenthaltes des Kaiserhofes aufgeführt wurden. ${ }^{28}$ In einigen Kirchen wurde offenbar auch Musik am Heiligen Grab in einer Art und Weise aufgeführt, wie sie von der nur wenig jüngeren bereits erwähnten Sepulkralmusik Zelenkas repräsentiert wird. Die erste zusammenhängende Tradition der Aufführung von umfangreicheren Oratorien italienischen Ursprungs ist allerdings gerade für die ganz neue Kleinseitner St.-Nikolaus-Kirche belegt, was im Lichte der weiter oben angeführten Tatsachen sicherlich nicht als Zufall wahrgenommen werden kann. In den Jahren 1714 und 1715 erklangen zwei Karfreitags-Oratorien von Carlo Francesco Cesarini, und beide wurden auf den Titelblättern der Libretti als eine aus Rom importierte Neuheit angekündigt. ${ }^{29}$ Ähnliches ereignete sich 1717, als ein weiteres Oratorium - diesmal aus Neapel und ohne Autorenangabe - erklang. ${ }^{30}$ Im Jahre 1716 folgte das Oratorium Gott-

tentum des Grafen Jan Hubert Hartigs bei der Prager Kreuzherren mit rotem Stern im Licht des Ordensarchivs]. Hudebni véda 50, 2014, im Druck.

28 NIUBÓ, Marc. Leopold I. a hudba císařského dvora v Praze v letech 1679-1680 [Leopold I. und die Musik des Kaiserhofes in Prag in den Jahren 1679-1680]. In Barokni Praha - Barokní Čechie 1620-1740 [Barockes Prag - Barockes Böhmen 1620-1740], Praha 2004, S. 95-131. Siehe auch DERS. Vincenzo Albrici u pražských jezuitů na konci 17. století [Vincenzo Albrici bei den Prager Jesuiten am Ende des 17. Jahrhunderts], In ČEMUS, Petronilla, ed. Bohemia Jesuitica 1556-2006. V Praze: Karolinum, 2010, Bd. 2, S. 1081-1094.

Poenitentia filii prodigi in lucem posita. Der Verlohrne Sohn. Voriges Jahr in Rom, jetzt aber in der kleinern Stadt Prag in der Kirchen S. Nicolai der Wohl-Ehrwürdigen PP. Soc. Jesu, am H. Char-Freytag von der Edlen Music befliessenen Liebhabern in einen traurigen Gesang entworffen. In die Music gesetzt von h. Carolo Francisco Cesarini. Alt-Stadt Prag: gedruckt bey Wolffgang Wickhart, Ertz-Bischoffl. Buchdrucker, 1714 (CZ Pu, 52 C 20, Adl. 27), ARSI, Boh. 127: „Die Sacrorum Parasceves, coram prima nobilitate et ingenti Religiosorum numerorum ad trihorium, selecta musica productum oratorium".

Constantis fiduciae messis uberior. Der nach langen Trauren, und Vertrauen mit reicher Trost-Ernde beglückte Tobias. Voriges Jahr in Rom auff kunstreiche Sing-Arten gesetzet, durch h. Carolum Franciscum Cesarini, anjetzo aber in der Kirchen S. Nicolai Societ. Jesu der kleinern Stadt Prag am heil. Char-Freytag Nachmittag um 12. Uhr zu andächtiger Behertzigung in hoch-teutscher Sprache melodisch vorgestellet von der edlen Music befliessenen Compagnie. Alt-Stadt Prag: Im Königs-Hoff gedruckt bey Wolffgang Wickhart, Hochfürstl. Ertz-Bischoffl. Buchdrucker, 1715., (CZ Pu, 52 C 20, Adl. 28), ARSI, Boh. 128, p. 10: ,Uti etiam Mortuo eidem gloriosum Sepulchrum est erectum die Parasceves, et ad id Oratorium Roma comparatum, typisque mandatum, coram Nobilissimo auditore, coninne [= consuetudine?] productum productum, novis etiam instrumentis, ad Chorum Musicum comparatis pretio 23 Rhenensium ".

30 Amoris in iudicio victoria oder Die obsiegende Liebe, in dem, wider das Menschliche Geschlecht, wegen dess grausamen Christi-Mords, von der göttlichen Berechtigkeit (!) angestellten Hals-Beriche, vormahls in Neapol, anjetzo aber in der Kirchen S. Nicolai Soc: Jesu, der königlichen kleinern Statt Prag, am h. Charfreytag nachmittag um 12. Uhr. zu andächtiger Betrachtung in hoch-teütscher Sprache melodisch vorgestellet, von einer Edlen MusicBefliessenen Compagnie. Cum Licentia Superiorum. Alt-Stadt Prag : gedruckt bey Wolffgang Wickhart, Ertz-Bischoffl. Buchdr., 1717. (CZ Pu, 52 C 20, Adl. 29). ARSI, Boh. 131, p. 7 : „Sepulchrum D[omi] ni in Parasceve accomodatum forit affectuoso ut vocant Oratorio, con- 
fried Heinrichs Stölzels Die büssende und versöhnte Magdalena, die nochmal 1726 in der Kreuzherrenkirche des H1. Franziskus aufgeführt wurde. ${ }^{31}$

Die Litterae annuae erwähnen die Aufführung von Karfreitagsmusik allerdings bereits für das Jahr 1713. ${ }^{32}$ Die Identität des Werkes ,, de Patiente Servato$r e$ " ist nicht ganz klar; es bietet sich jedoch das lateinische Oratorium Gottfried Heinrich Stölzels Jesus patiens an, das laut erhalten gebliebenem Libretto 1724 bei den Kreuzherren aufgeführt wurde und laut Dlabacž im gleichen Jahr auch noch in der Salvator-Kirche im Klementinum. ${ }^{33}$ Wenn nun Stölzels Oratorium über die Hl. Maria Magdalena 1716 in Prag geschrieben und aufgeführt wurde und zehn Jahre später noch einmal, können wir analog von einem ähnlichen Verlauf auch für das Oratorium Jesus patiens ausgehen, das Stölzel im Übrigen laut eigenen Angaben während seines Prager Aufenthaltes komponiert hatte? ${ }^{34}$ Dieser sollte unmittelbar auf die Rückkehr des Komponisten von seinem ItalienAufenthalt 1715-1717 folgen; wenn dieses Oratorium jedoch bereits 1713 aufgeführt wurde, musste der Komponist über Kontakte nach Prag bereits vor seinem Italien-Aufenthalt verfügt haben. In diesem Zusammenhang ist Dlabacžs Erwähnung darüber interessant, dass 1724 jenes Oratorium sowohl bei den Kreuzherren als auch in der Jesuitenkirche St. Salvator gegeben wurde. Nach heutigem Erkenntnisstand der Prager Aufführungspraxis von Oratorien, die sich eher durch Konkurrenz zwischen den einzelnen Kirchen als durch Zusammenarbeit bei der Aufführung eines Titels auszeichnete, ist die Aufführung desselben Titels in zwei verschiedenen Kirchen ziemlich unwahrscheinlich. War es also nicht eher so, dass sich Dlabacž oder seine Quelle irrte und die Information über die Aufführung im Klementinum in Wirklichkeit die Aufführung des gleichen Oratoriums elf Jahre früher ebenfalls bei den Jesuiten, allerdings in der St.-Nikolaus-Kirche reflektiert? Für die Verbindungen des Komponisten mit der genannten Kirche

centibus Musicis ad aurium animique delicias animato, delectis in id ex tota Triurbe Musurgis facile Principibus, quorum ope arteque politiore. "

Nur die zweite Aufführung ist auch durch ein Libretto belegt, POŠTOLKA, op. cit., Nr. 7 auf S. 101, und CZ Pu, Sign. 52 C 8, Adl 2. Zur ersten Aufführung siehe DLABACŽ, III, 215, MILLER, IV, 1345 und ARSI, Boh. 129, p. 8: „In Sepulchro Dominico proposita fuit Magdalena poenitens ad pedes Christi, e Cruce depositi, cui appositum fuit Oratorium tum a Sacra Poësi, tum ab affectu Musico valde commendatum, in Parasceve, a lectissimis Musicis coram Nobili eoque copioso Auditore, ad teneram devotionem, ultra trihorium, productum. Textus subinde Typis mandatus, et praefixa poenitentis Magdalenae imagine, liberaliter est distributus. “

32 ARSI, Boh. 126, p. 5: „Feriâ 6. Sanctionis hebdomadae, Tri Urbis Sacram et profanam Nobilitatem, cum accitis Clero, Asceteriis, et Magistratibus, affectuosi, et rarae artis, De Patiente Servatore, ad Ejusdem Sepulchrum, concentus Musici, per quadrihorium fere, nec sine plurimorum lachrymis, continuerunt."

POŠTOLKA, op. cit., Nr. 3 auf S. 100; CZ Pu, Sign. 52 C 8; DLABACŽ, Gottfried Johann. Allgemeines historisches Künstler-Lexikon für Böhmen und zum Theil auch für Mähren und Schlesien. Prag: Gottlieb Haase, 1815, Bd. III, 215.

MATTHESON, Johann. Grundlage einer Ehren-Pforte. Hamburg, 1740, Reprint Berlin: Liepmannssohn, 1910. 
spricht auch die ihm zugesprochene Pastorella, die ebenfalls den St.-NikolausMusikalien zugeordnet werden kann. ${ }^{35}$

Die Libretti der in den Jahren 1714-1717 zu St. Nikolaus aufgeführten Oratorien verfügen über einige bemerkenswerte gemeinsame Züge. Obwohl es sich ursprünglich um italienische Oratorien handelt, scheint es, dass zumindest zwei von ihnen in deutscher Übersetzung aufgeführt wurden, wie die Anmerkung ,,in hoch-teutscher Sprache melodisch vorgestellet" auf den Titelblättern der Libretti andeutet. Eine bestimmte Präferenz des Deutschen deutet auch Stölzels deutsches Oratorium von 1716 an. Die St.-Nikolaus-Kirche wurde jedenfalls im Rahmen des Kleinseitner Jesuiten-Komplexes als deutsch wahrgenommen, hier wurde deutsch gepredigt, und in der dortigen St.-Barbara-Kapelle traf sich die „deutsche Bruderschaft", während in der St.-Wenzels-Kirche tschechisch gepredigt wurde und dort auch die tschechische marianische Kongregation siedelte, während die lateinische Studenten-Sodalität im marianischen Oratorium des Gymnasiums zusammenkam. ${ }^{36}$ Das Libretto von 1715 beinhaltet darüber hinaus zwei Versionen des Textes, eine, die ,nach der Welschen Sing-Art in ungebundene Reim-Sätze eingezwungen "wurde, und die andere ,in gebundene Reim-Sätze“, die damals für Übersetzungen üblich war. ${ }^{37}$ Die Vorrede des Librettos aus dem Jahre 1717 belegt, dass das Problem der Übersetzung, aber auch die Forderung nach vollkommenem Verständnis des gesungenen Wortes damals offensichtlich sehr lebendig war:

An den Hoch-günstigen, Andacht-befliessenen Leser.

Weil man sich entschlossen, nicht allein die Kunst-mässige Wälsche Sing-Art in gegenwärtigem Oratorio unverändert zu behalten; sondern auch den Nachdruck der Wälschen Red-Art in Teutscher Sprache auffs möglichste nachzuähnen: So hat doch dieses letztere ohne Zwang der Hoch-Teutschen Mund-Art nicht allerseits können bewerckstelliget werden: Sintenmahl ein Vernünfftiger leichter achten wird, wie schwer es falle, ein Poësie auß einer Sprache in die andere, mit gleichen Syllaben und Verstande, mit Obachtung zugleich der Sing-Music zu überbringen.

So dann wird der geneygte Leser desto gutwilliger entschuldigen, wann da und dort etwelche Red-Arten wider die Reinigkeit der Teutschen Sprache, wider die Poësie und Reim-Kunst vorkommen werden. Unser Vorhaben ware allen in der Andacht zu dienen. Zu dem Ende wir diese Music den Ohren, diese wenige Blättlein den Augen deß Andachtbefliessenen Zuhörer-und Lesers dienstwilligst wollen gewidmet haben. ${ }^{38}$

Als ein nicht weiter kommentiertes Beispiel für die Verarbeitung beider Übersetzungen sei an dieser Stelle die Eingangsarie des Oratoriums Il Tobia aufgeführt, dass die Convictores des Jesuiten-Seminars in Rom 1714 aufführten und das ein Jahr später auch in der St.-Nikolaus-Kirche in Prag erklang:

35 CZ Pnm, Sign. XV A 193.

36 PODLAHA. Dějiny, S. 83.

37 Im Libretto aus dem Jahre 1715 sind zwei Versionen des Textes im unter Anm. 29 aufgeführten Exemplar erhalten geblieben, während das Exemplar CZ Pu, Sign. 52 C 32 nur die erste Version des Textes beinhaltet.

Amoris in iudicio victoria, p. [2]. Das Vorwort druckte als erster BUŽGA, op. cit., S. 169-170. 


\begin{tabular}{|c|c|c|}
\hline Italienisches Original 39 & ungebundene Reim-Sätze & gebundene Reim-Sätze \\
\hline $\begin{array}{l}\text { Zeffiretto, che placido spiri } \\
\text { Dici al core: quel Cielo, che miri } \\
\text { E'quel Cielo che vita ti diè. } \\
\text { Veggo l'onda, che scorre più } \\
\text { bella, } \\
\text { E soggiunge in sua dolce fa- } \\
\text { vella: } \\
\text { Il tuo porto lontano non è. }\end{array}$ & $\begin{array}{l}\text { Milder Zephyr dein liebliches Wehen, } \\
\text { Sagt mir Schertzen, } \\
\text { Mir zum Hertzen, } \\
\text { Ich solle verstehen: } \\
\text { Daß ich nahe dem Vatterland sey. } \\
\text { Helles Bächlein in mostigen Klippen, } \\
\text { Wilst mir sagen mit zisplenden Lippen } \\
\text { Meine Ruhe komm' nahe herbey. }\end{array}$ & $\begin{array}{l}\text { Du holder Zephyr Wind, } \\
\text { Ich denck' dein laues Wehen, } \\
\text { (kann ich dich sonst verstehen) } \\
\text { Daß sagt mir sanfft und lind: } \\
\text { Ich sey' dem Himmel nahe, } \\
\text { Den ich mit Luft besahe } \\
\text { Da ich noch war ein Kind! } \\
\text { Crystallen-reiner Fluß, } \\
\text { Der du von hellen Quellen } \\
\text { Versammlet deine Wellen, } \\
\text { Und mit geschlangtem Guß, } \\
\text { Besafftest Thal und Auen, } \\
\text { Du sag'st mir in Vertrauen: } \\
\text { Es steh' am Port mein Fuß. }\end{array}$ \\
\hline
\end{tabular}

Tab. 1: Die Eingangsarie des Oratoriums Il Tobia

Neugierig machen auch die ,edle Music-befliessene Liebhaber“ beziehungsweise „...Compagnie”, die die Oratorien laut der Titeltexte aufführte; im Übrigen verfügt auch das Libretto zur späteren Wiederaufführung von Stölzels Die Büssende und Versöhne Magdalena aus dem Jahre 1726 - diesmal schon bei Kreuzherren - über eine Bemerkung über „einer Löblichen Edlen Music-Befliessenen Compagnie“. Die bestehenden Arbeiten zu Oratorien in den böhmischen Ländern vertreten die Ansicht, dass diese Werke von (adeligen) Studenten des Kleinseitner Jesuiten-Gymnasiums aufgeführt wurden. ${ }^{39}$ Es ist möglich, dass dieser Gedanke auf der irrtümlichen Verbindung von zwei unterschiedlichen Aufführungen fußt: 1714 hatte nämlich das von den Studenten des Kleinseitner Gymnasiums zum Abschluss des Schuljahres aufgeführte Hauptstück das gleiche Thema wie das Karfreitags-Oratorium, nämlich das Gleichnis vom verlorenen Sohn. ${ }^{40}$ Natürlich kann nicht ausgeschlossen werden, dass das Oratorium von adeligen Studenten oder (ähnlich wie in Rom) von Seminaristen aufgeführt wurde. Die Bezeichnung „edle Music-Befliessene Compagnie“ scheint aber in seltener Eintracht mit Stölzels Schilderungen des Prager Musiklebens zur Zeit seines dortigen Aufenthaltes zu sein, dem die Musikalische Akademie und die musikaffinen Adeligen Hartig, Losy und Anthony von Adlersfeld dominierten. Das zielt also eher auf die musikaffine Prager Elite und auf die Musiker, die in deren Diensten standen, womit er auch andeutet, dass die Karfreitags-Oratorien im Leben der Stadt bereits von Beginn an eine Dimension erlangten, die über ihre primäre Funktion der religiösen Meditation hinausging. Ob und welche Oratorien in den darauf folgenden Jahren

39 LAUŠMAN, Josef. Pražské oratorium století XVIII. [Das Prager Oratorium im 18. Jahrhundert.] Diss. Karlsuniversität Prag, 1938; FREEMANOVÁ, Michaela. Oratorium (and opera) of the German composers as performed in the Czech Lands in the 18th and 19th centuries. In Deutschsprachiges Theater in Prag, Praha 2001, S. 195-204. verlohrne Sohn luca am 15. Cap. zur Nachricht und Warnung der Ungerathenen freyen Jugend... Pragae: [s.n.], 1714, CZ Pu, Sign. 52 A 19. 
in der St.-Nikolaus-Kirche aufgeführt wurden, ist nicht bekannt. Die benachbarten Kirchen St.-Franziskus-Serafin und St. Salvator auf dem anderen Moldauufer sind allerdings kurz darauf - und das ganze 18. Jahrhundert hindurch - zu den zentralen Prager Orten für Oratoriums-Aufführungen geworden. ${ }^{41}$

$* * *$

Eine weitere Schicht des musikalisch-liturgischen Betriebes in der St.-NikolausKirche stellten die Andachten der geistlichen Bruderschaften dar. Von diesen Bruderschaften interessiert uns besonders die vereinigte Totenbruderschaft Agonizantium et mortui, die genauso wie die deutsche Bruderschaft der Heiligen Barbara in der dieser Heiligen geweihten Kapelle zusammenkamen. Deshalb befinden sich in der Kapelle der Hl. Barbara, die als eine der ersten in der neuen Kirche errichtet wurde, auch zwei Altare, wobei dem Altar der Bruderschaft der Todesangst Christi das berühmte Gemälde Kreuzigung mit Maria und den Seelen im Fegefeuer von Karel Škréta dominiert, das aus der alten Kirche hierher gebracht wurde. ${ }^{42}$ Wie bereits erwähnt, hat man in der Stiftung der Bruderschaft der verstorbenen Brüder (Coetus defunctorum) ausdrücklich an die Musik gedacht: Die regelmäßigen Totenmessen sollten ,,durch Messen und Music aufs beste verrichtet " 43 werden. Gerade für diese Bruderschaft sollte der Komponist Johann Joseph Ignaz Brentner seine Trauermotetten komponieren, und somit gelangen wir wieder zur Problematik der Musikaliensammlung von St. Nikolaus.

Die bereits erwähnten Musikalien aus der ehemaligen St.-Nikolaus-Sammlung erhielt Ondřej Horník zu Beginn des 20. Jahrhunderts vom Prager Kirchenamt (Zádušní úřad); sie sind aufgrund der Vermerke Horníks auf den Titelblättern (,Darem ze zádušního úřadu Král. Hl. Města Prahy“) allesamt leicht zu identifizieren. Einige Musikalien sind allerdings wahrscheinlich in St. Nikolaus geblieben und heute in verschiedenen Sammlungen verstreut. Im Tschechischen Musikmuseum sind insgesamt fünf Kompositionen Brentners pro defunctis erhalten geblieben. Mit Ausnahme des Cantus für zwei Gesangsstimmen, zwei Instrumente und Generalbass „,Herr, ich hab geliebet Dich“ (CZ Pnm VI C 217, HorníkSammlung) handelt es sich um vierstimmige Trauermotetten, die von zwei Vio-

41 Für die Zwecke dieser Studie habe ich in ARSI lediglich die Litterae annuae der Jahre 1710 1717 exzerpiert. Das Studium der Dokumente konnte nur dank der Unterstützung des Tschechischen Historischen Instituts in Rom, dem ich hiermit danke, realisiert werden. Für die Revision der Exzerpte aus der Litterae annuae danke ich Kateřina Bobková-Valentová.

42 Weitere Informationen über die Bruderschaften, die Kapelle und Škrétas Gemälde einschließlich seiner Reproduktionen vgl. MIKULEC, Jiří. Náboženská bratrstva - institucionalizovaná zbožnost i smrt [Religiöse Bruderschaften - institutionalisierte Frömmigkeit und Tod]. In HOLÝ, Martin, ed. - MIKULEC, Jiří, ed. Církev a smrt: institucionalizace smrti $v$ raném novověku $=$ Church and death: the institutionalization of death in the early modern times. Praha: Historický ústav, 2007, S. 163-186 und OULÍKOVÁ, Petra. Künstlerische Ausstattung von Altären und Kapellen der von Jesuiten betreuten Bruderschaften in Prag. In Bohemia Jesuitica 1556-2006, Praha: Karolinum, 2010, Bd. 2, S. 1217-1238.

NETTL, op. cit., S. 115. 
linen und einem Generalbass begleitet wurden, die jedoch nicht Bestandteile der Horník-Sammlung sind, sondern von Emilián Trolda spartiert, beschrieben und dem Nationalmuseum geschenkt wurden. ${ }^{44}$ Später, während des Krieges, wurde diese Musik anhand von Spartierungen Troldas in der Reihe Erbe deutscher Musik durch Theodor Veidl herausgegeben. ${ }^{45}$ Veidl im Vorwort dieser Edition genauso wie Milan Poštolka im Text zum Schlagwort Brentner in The New Grove Dictionary of Music sprechen über den Bestimmungszweck der Motetten, dieser ist aus den Quellen selbst jedoch nicht offensichtlich ableitbar: die übliche Notiz "Chori Sancti Nicolai“ ist dort nicht aufgeführt, eine andere Informationsquelle führen die erwähnten Autoren allerdings nicht an.

Aus Troldas in seinen Studien und Spartierungen verstreuten Bemerkungen geht hervor, dass er die betreffenden Motetten gemeinsam mit anderen Kompositionen aus dem Nachlass des 1919 verstorbenen Regenschori von St.-Nikolaus, Karel Bautzký, erhielt. Bautzký war ein Absolvent der Organistenschule und im Fach Komposition ein Schüler von Fibich und Dvořák. Er war als Organist u.a. in der Teyn-Kirche tätig und später auch als Regenschori in St. Nikolaus aktiv. ${ }^{46}$ Trolda erhielt von Bautzký offenbar schon zu seinen Lebzeiten Jacobs gedruckte Sammlung Acratismus pro honore Dei (Prag 1725), aus dem Nachlass bekam er dann weitere Einzeldokumente, die er spartierte und 1931 dem Nationalmuseum übereignete. Außer Brentners Motetten handelte es sich um Kompositionen von F. X. Brixi, Gayer, Reichenauer u.a.; einen Teil der Sammlung Bautzkýs erwarb angeblich auch Romuald Perlík für das Strahov-Archiv. ${ }^{47} \mathrm{Zu}$ den Musikalien aus Bautzkýs Nachlass gehört wohl auch Plánickýs Solomotettendruck Opella ecclesiastica, den Trolda laut eigener Aussage ,, in den Resten der Prager St.-Nikolaus-Musikalien " gefunden hat. ${ }^{48}$ Im Kompositionsnachlass von Karel Bautzký, der sich im Tschechischen Musikmuseum befindet, befinden sich leider keine Musikalien aus dem 18. Jahrhundert. ${ }^{49}$ Über die Provenienz der Brentnerschen Motetten informierte Bautzký Trolda offenbar mündlich.

44 Es handelt sich um die Kompositionen Himmelssonne, uns erquicke; Sag was ist diese Welt?; Jesu, du mein treuer Hirt; O Jesu mein, CZ Pnm, Sign. XV D 359-362. Troldas Spartierungen befinden sich auch in CZ Pnm, Sign. XXVIII F 224-227.

Prager deutsche Meister: der ersten Hälfte des 18. Jahrhunderts: Chorwerke. Theodor VEIDL, ed. Reichenberg: Ullman, 1943. Das Erbe deutscher Musik II/4. Siehe auch VOLEK, Tomislav. Emilián Trolda a edice pražských mistrů v Das Erbe Deutscher Musik II/4 [Emilián Trolda und die Edition Prager Meister in EdM]. Hudební véda 37, 2000, č. 3-4, S. 239-241.

46 Siehe Československý slovník osob a institucí. Bd. 1. Praha 1963, Art. Bautzký, S. 67.

47 BUCHNER, Alexander. Hudebni sbirka Emiliána Troldy [Die Musiksammlung von Emilián Trolda]. Praha: Národní muzeum, 1954, S. 6-7.

48 TROLDA, Emilián. Z české barokní hudby [Aus der böhmischen Barockmusik]. Cyril 63, 1937, č. 9-10, s. 105-107. Diese Exemplar der Opella ecclesiastica befindet sich heute in CZ Pnm, Sign. XVIII F 355.

49 Für die Konsultation und das freundliche Ermöglichen eines Einblicks in diesen bisher unbearbeiteten Fonds danke ich Markéta Kabelková. Bautzkýs Nachlass-Akte befindet sich im Archiv der Hauptstadt Prag, Sign. A 498/19. Sie beinhaltet kein Inventar des Nachlasses: der 
Es handelt sich dabei um Quellen, die sowohl hinsichtlich ihres Inhalts als auch ihrer Gestalt einzigartig und bemerkenswert sind. Bei drei davon handelt es sich mit allergrößter Wahrscheinlichkeit um Autografe des Komponisten, was auch auf deren Titelblatt vom ehemaligen Direktor des Museums Emil Axman mit Bleistift vermerkt wurde. Es handelt sich dabei um Stimmen, die von einer markanten und charakteristischen Handschrift geschrieben wurden; interessant ist unter anderem die Verwendung von Kapitälchen im Titeltext, und das auf Papier ohne sichtbares Wasserzeichen. Die Autograf-Hypothese wird vor allem durch die Tatsache gestützt, dass sich in der Musikalienabteilung des Benediktinerklosters in Göttweig - einer der bedeutendsten Fundorte von Kompositionen Brentners - einige äußerst ähnliche Handschriften befinden, geschrieben von der gleichen Hand auf ähnlichem Papier, die im Unterschied zu den meisten anderen Handschriften in dieser Sammlung ihren Ursprung nicht in Göttweig haben. ${ }^{50}$ Die Motette $O$ Jesu mein wurde von der Hand eines unbekannten Kopisten geschrieben, einige Merkmale seiner Arbeit wie z.B. die auffällige Verwendung von Kapitälchen im Wort Authore im Titeltext deuten darauf hin, dass es sich um die Abschrift von Material handeln könnte, das von der hypothetischen Komponistenhand geschrieben wurde. An dieser Stelle ist kein Raum dafür, sich näher mit der Musik auseinanderzusetzen, auf jeden Fall handelt es sich aber um einen für die damalige Zeit und den damaligen Ort wertvollen Beleg von Kirchenmusik auf einen deutschen Text. ${ }^{51}$

Ausgehend von den römischen Zahlen in der Kopfzeile der Titelblätter der drei wahrscheinlichen Autografe kann davon ausgegangen werden, dass es sich ursprünglich um eine Gruppe von mindestens 16 Kompositionen handelte. Noch interessanter sind die Aufführungsdaten, die auf der letzten Seite des Umschlages vermerkt sind. Angegeben sind lediglich die Tage ohne Jahresangabe (siehe Tab. 2). Dennoch kann man die Kompositionen auf dieser Grundlage relativ zuverlässig datieren. Laut Angaben des erhalten gebliebenen Gedenkbuches der Bruderschaft der Todesangst Christi fanden die regelmäßigen wöchentlichen Andachten für die Verstorbenen am Montag statt (falls dieser Tag auf einen Feiertag fiel, am Dienstag oder Mittwoch) und zwar um vier Uhr nachmittags. ${ }^{52}$ Und tatsächlich sind alle auf den Brentnerschen Motetten angeführten Daten die Daten

letzte Wille wurde nicht aufgefunden, der geschiedene Bautzký hatte kein Vermögen und die Einrichtung der Kleinseitner Wohnung wurde zum Eigentum Barbora Bemlovás erklärt, bei der er lebte.

50 Es handelt sich um: Missa Divi Angeli Custodis, Requiem solemne und Missa Dominicalis, A GÖ, Sign. 45-47. Siehe auch RIEDEL, Friedrich W. Der Göttweiger thematische Katalog von 1830. München: Katzbichler, 1979.

51 Die Aufnahme wurde auf CD herausgegeben Jan Josef Ignác Brentner [Auswahl von Motetti pro defunctis, Ofertoria solenniora op. 2 und Harmonica duodecatomeria ecclesiastica op. 1], Ensemble Inégal, Adam Viktora, Praha 2003, Nibiru 0144-2211.

52 NA, Bestand Náboženská bratrstva [Bruderschaften] (NB), Sign. XVII/57, Kart. 133, p. 12. Siehe auch NETTL, S. 115-116. 
eines Tages im Verlaufe eines Jahres, der Montag fällt dann entweder auf das Jahr 1717 oder 1723. Angesichts der Tatsache, dass Brentners Aufenthalt in Prag vor allem für die Jahre 1716-1720 als wahrscheinlich angenommen wird, als dort vier gedruckte Sammlungen seiner Kompositionen herausgegeben wurden, scheint das Jahr 1717 der wahrscheinlichste Kandidat für die Entstehung dieser Motetten zu sein.

\begin{tabular}{|l|l|lllll|}
\hline Komposition & Römische Zahl & Aufführungsdaten & \\
\hline Himmelssonne, uns erquicke & X. & Jan. & Maji. & Julii & Aug. & 27. \\
& & 4. & 10. & 19. & 9. & 7 bris \\
\hline Sag was ist diese Welt? & XII. & Febr & Apr. I & 5. Julii & Aug. \\
& & 1. & 19. & 30. & \\
\hline Jesu, du mein treuer Hirt & XVI. & Jan & Apr. & Jun. & Jun. & Aug. \\
& & 18. & 13. & 7 & 28. & 23. \\
\hline
\end{tabular}

Tab. 2: die Aufführungsdaten auf der letzten Seite des Umschlages

$$
* * *
$$

Leider ist bis auf Ausnahmen nicht bekannt, welche Prager Musiker am St.Nikolaus-Chor in der ersten Hälfte des 18. Jahrhunderts tätig waren. ${ }^{53}$ Eine klare Vorstellung über die Gestalt des Musikensembles vermitteln jedoch die „Dispositiones pro Musicis in Domo Professa ad S: Nicolaum “, die im Jahre 1739 neu formuliert wurden. Die Dokumente gab ohne ausführlichere Kommentare Paul Nettl heraus, allerdings blieb seine Edition bis heute mehr oder weniger unbeachtet. ${ }^{54}$ Die betreffenden Dokumente sind bis heute im Torso des Archivs des Provinzprokurators im Bestand Jesuitica im Nationalarchiv erhalten geblieben. ${ }^{55}$ Im alten Katalog dieses Archivs sind zwei weitere musikspezifische Dokumente erfasst: das Gehaltsbuch der Musiker für die Jahre 1740-1742 und vor allem die Rechnungsbücher des Kantors des Professhauses aus den Jahren 1668-1701. ${ }^{56}$ Diese Dokumente konnten jedoch leider nicht ausfindig gemacht werden; sie sind wahrscheinlich nicht erhalten geblieben.

Im Falle der Dispositiones pro Musicis handelt es sich dabei um Anweisungen für die Musik bei den Andachten der Totenbruderschaft, Instruktionskonzepte für Musiker, Aufstellungen der jährlichen Ausgaben für Musik, der Gehälter der Musiker sowie Ausgaben für unterschiedlichste Zuschüsse und Beigaben ( $a c$ cidentales, collationes) oder die definitive Version der neuen Instruktionen für das Musikensemble. Dieses umfasste damals 16 Instrumentalisten und erwachsene Sänger („Virtuosi“): 2 Tenöre, 2 Bässe, 4 Violinisten, von denen einer oder zwei gleichzeitig auch Oboe oder Querflöte spielen konnten, des Weiteren einen

53 Ein Verzeichnis der Organisten zusammengestellt auf der Grundlage der Angaben von Trolda und Dlabacž bei NĚMEC, Vladimír. Pražské varhany. Praha: František Novák, 1944, S. 145; ein Verzeichniss der Prefekten musicae bei HOLUBOVÁ, op. cit. 
Violoncellisten, einen Violone-Spieler, den ersten Oboisten und 4 Trompeter. Einschließlich Organist, 3 Diskantisten, 2 Altisten und eines Kalkanten waren 1739 insgesamt 23 Personen für die Musik in St. Nikolaus verantwortlich.

Aus der Aufstellung der Accidentien geht unter anderem hervor, dass die St.Nikolaus-Musiker alljährlich auf dem Heiligen Berg spielten, einem bekannten jesuitischen Wallfahrtsort in Př́bram. Das erklärt im Nachhinein den Grund, warum der Prager Komponist Antonín Reichenauer für die St.-Nikolaus-Kirche eine Cantata de B. V. M. ad Montem Sanctam komponierte, deren Autograf-Stimmen in der Horník-Sammlung erhalten geblieben sind.$^{57}$ Laut Eigentumsnotiz auf der Titelseite der Komposition ist das Werk 1723 in die St.-Nikolaus-Sammlung übergegangen, sie entstand also höchstwahrscheinlich im selben Jahr oder kurz davor. Im Grunde genommen handelt es sich um eine Bass-Da-Capo-Arie, die von einem kurzen Rezitativ eingeleitet wird. Die Komposition gefällt vor allem mit ihrer Instrumentalbegleitung, die aus ambitionierten Solo-Stimmen für Violine, Oboe und Fagott mit Generalbass-Begleitung besteht. Das korrespondiert beispielsweise mit jenen Instrumentalkonzerten, die der gleiche Komponist damals für die Kapelle des Grafen Wenzel Morzin komponierte, die überwiegend aus Kleinseitner bzw. Prager Musikern bestand. ${ }^{58}$ Waren einige von ihnen gleichzeitig im St.-Nikolaus-Chor aktiv?

Ein letzter Blick auf den Chor der jesuitischen St.-Nikolaus-Kirche soll nun aus der Perspektive von Jan Dismas Zelenka geworfen werden. Dieser komponierte 1704 für das Gymnasium bei dem Kleinseitner Professhaus die Musik für eine Huldigungsvorstellung zu Ehren des Grafen Hermann Jakob Czernin mit dem Titel Via laureata. Wie wir wissen, handelt es sich dabei um die überhaupt erste bekannte Komposition Zelenkas, die allerdings aus einer gedruckten Synopse bekannt ist. ${ }^{59}$ Die Prager Jesuiten standen natürlich mit ihrem ehemaligen Schüler weiter in Kontakt, und seine Musik wurde auf den Chören (nicht nur) der jesuitischen Kirchen in Prag gespielt. Es ist bezeichnend, dass die einzigen Prager Notenquellen zu Zelenkas Musik aus dem jesuitischen Milieu just aus der Sammlung der St.-Nikolaus-Kirche stammen. Gut bekannt sind die Abschriften zweier Messen, die sich in der Nationalbibliothek befinden, von der sie 1960 erworben wurden (ob es sich um einen weiteren Restbestand der Sammlung von Karel Bautzký handelt, ist nicht klar): es handelt sich um die älteste bekannte Abschrift von Zelenkas Missa nativitatis ZWV 8 datiert aus dem Jahre 1736 und um eine Abschrift der Messe D-Dur ZWV 23, deren Autorenschaft umstritten ist. ${ }^{60}$ Aus den Nummern auf den Titelblättern kann geschlussfolgert werden, dass

57 CZ Pnm, Sign. XIV B 205. Die Komposition wurde auf CD eingespielt Rorate coeli. Advent and Christmas in Baroque Prague. Collegium Marianum, Jana Semerádová. Praha: Supraphon, 2009, SU 4002-2.

58 Näher dazu bei KAPSA, Václav. Hudebníci hraběte Morzina [Die Musiker des Grafen Morzin]. Praha: Etnologický ústav Akademie věd České republiky, 2010.

59 Die Synopse edierte als Anhang 1 seiner Studie VOLEK, Tomislav. Zelenka Studien 1, S. 29-35.

60 CZ Pu, Sign. 59 R 2032 und 2033. Beide Quellen wurden digitalisiert und sind online zu studieren: http://www.manuscriptorium.com/ [zit. 1. 4. 2014]. 
es sich ursprünglich um eine Gruppe von mindestens fünf Messen gehandelt hat - wurden vielleicht auch die heute verschollenen Messen No. 1-3 von Zelenka komponiert?

Diese beiden Quellen können nun um eine dritte vervollständigt werden, die aus dem Jahre 1751 stammt, also der Endphase des von uns betrachteten Zeitraums. Es handelt sich um eine Abschrift von Zelenkas Litaniae Lauretanae „Salus infirmorum" ZWV 152, die Zelenka 1741 seinem ehemaligen Herren und Lehrer, dem sterbenden Grafen Johann Hubert Hartig und später der kranken Kurfürstin Maria Josepha gewidmet hatte. ${ }^{61}$ Die Widmungspartitur bekamen nach Hartigs Tod die Kreuzherren, die 1751 daraus einzelne Stimmenauszüge besorgten. ${ }^{62}$ Ein weiterer Stimmensatz stand im gleichen Jahr dem St.-NikolausChor zur Verfügung. ${ }^{63}$ Keiner dieser Stimmensätze beinhaltet die Oboen-Stimmen, das deutet darauf hin, dass die St.-Nikolaus-Stimmen eine bloße Kopie der Kreuzherren-Stimmen sind. Sie beinhalten zwar einige Fehler, die bei der Besorgung von Stimmauszügen aus Partituren typisch sind wie beispielsweise die falsche Einordnung von Noten aus einer Stimme in die andere, was auf Versehen der Kopisten zurückgeht. Wir wissen aber nicht, ob diese Fehler bei der Erstellung der Stimmauszüge aus Hartigs Partitur entstanden sind oder ob sie nur aus den Kreuzherren-Stimmen übertragen wurden ${ }^{64}$ Es ist allerdings paradox, dass die Litaneien dort als anonym figurierten, als wenn sich keiner der St.-NikolausMusiker mehr an seinen berühmten Vorgänger und Kollegen hat erinnern können.

Im gleichen Jahr wurde der monumentale Bau fertig gestellt, im darauffolgenden Jahr der schlanke Glockenturm vollendet. Die Jesuiten wirkten noch 20 Jahre in der Kirche, bevor sie nach der Auflösung des Ordens erneut zum Sitz der Pfarrei wurde; gerade aus diesem zwanzigjährigem Zeitraum stammen die meisten in der Horník-Sammlung erhalten gebliebenen St.-Nikolaus-Musikalien aus der Jesuitenzeit. Weitere Musikalien stammen aus der Zeit nach der Auflösung des Ordens, als St. Nikolaus wieder zur Pfarrkirche wurde; auch in diesem Zeitraum verzeichnete die musikalische Geschichte der St.-Nikolaus-Kirche eine Reihe denkwürdiger Momente. Als unübersehbare Dominante des Prager Panoramas stellt sie jedoch vor allem eine ewige Erinnerung an die bemerkenswerte Blüte des Prager Barock dar. Eine weniger auffällige, aber ähnlich wichtige Bedeutung hat sie aufgrund der erhalten gebliebenen Musik auch für die Musikgeschichte der Stadt.

\section{Deutsch von Ivan Dramlitsch.}

61 Herausgegeben von Thomas Kohlhase in Das Erbe deutscher Musik. Bd. 101. Wiesbaden: Breitkopf \& Härtel, 1989.

62 Siehe RISM online, http://opac.rism.info/search?documentid=550401391 und http://opac. rism.info/search?documentid=550255308 [zit. 1. 4. 2014].

63 CZ Pnm, Sign. XXIX E 128: Litaniae Lauretanae $|\grave{a}|$ Canto. $\mid$ Alto | Tenore. | Basso | Violinis $2^{\text {bus }} \mid$ Viola $|\&|$ Organo. | [Horník: Darem ze zádušního úradu |Král. hl. města Prahy 19 21/9 01] Chori Micro-Pragensis | Soc[ieta]tis JESU. 1751.

64 Der Vergleich aller Prager Quellen wurde aufgrund der schweren Zugänglichkeit der Kreuzherren-Sammlung nicht vorgenommen. 
Václav Kapsa (kapsa@imus.cas.cz), Kabinet hudební historie, Etnologický ústav AV ČR, v. v. i., Puškinovo nám. 9, 16000 Praha.

\section{ABSTRACT \\ MUSIC IN ST. NICHOLAS CHURCH IN THE LESSER TOWN OF PRAGUE DURING THE FIRST HALF OF THE $18^{\mathrm{TH}}$ CENTURY}

The present study intends to suggest various directions which the research might take in relation to the music at the Jesuit church of St. Nicholas in the Lesser Town of Prague in the first half of the 18th century. Based on the music-related sources, several specific issues are elaborated: the oratorios played there during the $1710 \mathrm{~s}$, the compositions written for the Confraternity of Death by Jan Josef Ignác Brentner, the music ensemble of the church and the sources of music by Jan Dismas Zelenka originating in the former St. Nicholas music collection. At the same time the article draws a parallel between the monumental and radical Baroque architecture of the new church, which changed the face of the city, and the no less important position, which the music of the Lesser Town Jesuits occupied in the Prague musical landscape of the time.

\section{Key words}

St. Nicolas Church, Lesser Town of Prague, Baroque, Jesuit order, church music, $18^{\text {th }}$ century

\section{Sources}

Amoris in iudicio victoria. Alt-Stadt Prag: gedruckt bey Wolffgang Wickhart, Ertz-Bischoffl. Buchdr., 1717.

Archiv Hlavního města Prahy [Archiv der Hauptstadt Prag], FÚ u sv. Mikuláše na Malé Straně [Bestand der Pfarrgemeinde von St. Nikolas auf der Kleinseite], i. č. 66, Kart. 3; Sign. A 498/19.. Archivum Romanum Societatis Iesu (ARSI): Boh. 124, 125, 126, 127, 128, 129, 131.

BRENTNER, Jan Josef Ignác: Missa Divi Angeli Custodis, Requiem solemne, Missa Dominicalis, A GÖ, Sign. 45-47; Herr, ich hab geliebet Dich, CZ Pnm, Sign. VI C 217; Himmelssonne, uns erquicke, Sag was ist diese Welt?, Jesu, du mein treuer Hirt, O Jesu mein, CZ Pnm, Sign. XV D 359-362, XXVIII F 224-227.

CESARINI, Carlo Francesco: Il Tobia. Roma, 1714; Poenitentia filii prodigi in lucem posita. AltStadt Prag: gedruckt bey Wolffgang Wickhart, Ertz-Bischoffl. Buchdrucker, 1714; Constantis fiduciae messis uberior. Alt-Stadt Prag: Im Königs-Hoff gedruckt bey Wolffgang Wickhart, 1715. CESARINI, Carolo Francisco. FEDELI, Vesperae. CZ Pnm, Sign. XIII F 52.

JACOB, Wenzel Gunther. Acratismus pro honore Dei. Prag, Paul Lochner, 1725; Mottetum de S.

Patre Ignatio. CZ Pnm, Sign. X F 121. Libertas Adolescentiae Castigata Pragae: [s.n.], 1714.

MAJER, Wenzel. Dixit Dominus, O Panis caelice. CZ Pnm, Sign. XII B 136, 137.

MILLER, Joannes. Historia provinciae bohemiae Societatis Jesu ab Anno Domini 1555 ... ad annum 1723. Liber IV, V et VI. CZ Pu, Sign. XXIII.C.104/3.

Národní archiv, Jesuitica (JS), Kart. 10, Mappe II/2/11; II/2/14; Sign. inv.15, Kart. 218.

Národní archiv, Náboženská bratrstva (NB), Sign. XVII/57, Kart. 133.

PEZ, Johann Christoph. Vesperae de Beatissima Virgine. CZ Pnm, Sign. XIII F 52.

PLÁNICKÝ, Josef Antonín. Opella ecclesiastica. CZ Pnm, Sign. XVIII F 355.

REICHENAUER, Antonín. Cantata de B. V. M. ad Montem Sanctam. CZ Pnm XIV B 205.

RUMPELNIG, Franz. Requiem. CZ Pnm, Sign. XIV F 39.

STÖLZEL, Gottfried Heinrich. Pastorella. CZ Pnm, Sign. XV A 193.

[ZELENKA, Jan Dismas]. Litaniae Lauretanae. CZ Pnm, Sign. XXIX E 128. 
ZELENKA, Jan Dismas: Missa nativitatis ZWV 8, Missa D dur ZWV 23. CZ Pnm 59 R 2032, 59 R 2033.

\section{Bibliography}

BAŽANT, Jan - BAŽANTOVÁ, Nina. Svatý Mikuláš na Malé Straně: největší barokní chrám v Praze [St. Nikolaus auf der Kleinseite: Die größte Prager Barockkirche]. Praha: Festina Lente Press, 2011.

BOBKOVÁ-VALENTOVÁ, Kateřina. Každodenní život učitele a žáka jezuitského gymnázia [Der Alltag von Lehrern und Schülern des Jesuiten-Gymnasiums] Praha: Karolinum, 2006.

BUBEN, Milan M. Encyklopedie řádů, kongregací a řeholních společností katolické církve v českých zemích. III. díl, 4. svazek: Řeholní klerikové (jezuité) [Enzyklopädie der Orden, Kongregationen und Ordensgesellschaften der katholischen Kirche in den böhmischen Ländern. II. Teil, 4. Band: Ordenskleriker (Jesuiten)]. Praha: Libri, 2012.

BUCHNER, Alexander. Hudební sbírka Emiliána Troldy [Die Musiksammlung von Emilián Trolda]. Praha: Národní muzeum, 1954.

BUŽGA, Jaroslav. Einige Quellen zur Geschichte der Osteroratorien in Prag und Brno (Brünn) und der Ostermelodramen aus Olomouc (Olmütz) im 18. Jahrhundert. In De musica disputationes Pragenses. Prag: Academia Verl. der Tschechoslowakischen Akademie der Wissenschaften, 1972, S. 151-171.

BRENTNER, Jan Josef Ignác [CD Audio] [Auswahl von Motetti pro defunctis, Ofertoria solenniora op. 2 und Harmonica duodecatomeria ecclesiastica op. 1], Ensemble Inégal, Adam Viktora, Praha 2003, Nibiru 0144-2211.

Československý slovník osob a institucí. Bd. 1. Praha 1963.

DLABACŽ, Gottfried Johann. Allgemeines historisches Künstler-Lexikon für Böhmen und zum Theil auch für Mähren und Schlesien. Prag: Gottlieb Haase, 1815.

FREEMANOVÁ, Michaela. Oratorium (and opera) of the German composers as performed in the Czech Lands in the 18th and 19th centuries. In Deutschsprachiges Theater in Prag, Praha 2001, S. 195-204.

HELFERT, Vladimír. Jiří Benda: příspěvek k problému české hudební emigrace = Georg Benda: Zum Problem der böhmischen Musikemigration. Bd. I. Brno: Filosofická fakulta s podporou Ministerstva školství a národní osvěty, 1929.

HOLUBOVÁ, Markéta. Biografický slovník hudebních prefektů jezuitského řádu působících v Čechách, na Moravě a ve Slezsku v letech 1556-1773 / Biographical dictionary of musical prefects of the Jesuit order active in Bohemia, Moravia and Silesia in the years 1556-1773. Praha : Etnologický ústav Akademie věd České republiky, 2009

JEŻ, Tomasz. Kultura muzyczna jezuitów na Śląsku i ziemi kłodzkiej (1581-1776) [Die Musikkultur der Jesuiten in Schlesien und im Glatzer Land]. Warszawa: Sub Lupa, 2013.

KAMPER, Otakar. Hudební Praha v XVIII. věku [Das musikalische Prag im 18. Jahrhundert]. Praha: Melantrich, 1936.

KAPSA, Václav - PERUTKOVÁ, Jana - SPÁČILOVÁ, Jana. Some remarks on the relationship of Bohemian aristocracy to Italian music at the time of Pergolesi. In Studi pergolesiani - Pergolesi studies 8. Bern, Peter Lang, 2012.

KAPSA, Václav. Hudebníci hraběte Morzina [Die Musiker des Grafen Morzin]. Praha: Etnologický ústav Akademie věd České republiky, 2010.

LAUŠMAN, Josef. Pražské oratorium století XVIII. [Das Prager Oratorium im 18. Jahrhundert.]. Diss. Karlsuniversität Prag, 1938.

MATTHESON, Johann. Grundlage einer Ehren-Pforte. Hamburg, 1740, Reprint Berlin: Liepmannssohn, 1910. 
MIKULEC, Jiří. Náboženská bratrstva - institucionalizovaná zbožnost i smrt [Religiöse Bruderschaften - institutionalisierte Frömmigkeit und Tod]. In HOLÝ, Martin, ed. - MIKULEC, Jiř́í, ed. Církev a smrt: institucionalizace smrti v raném novověku $=$ Church and death: the institutionalization of death in the early modern times. Praha: Historický ústav, 2007, S. 163-186.

MUCHKA, Ivan. St.-Nikolauskirche auf der Prager Kleinseite. Regensburg: Schnell \& Steiner, 1995.

NĚMEC, Vladimír. Pražské varhany. Praha: František Novák, 1944.

NETTL, Paul. Akten zur Geschichte und Organisation der Prager Kirchenmusik im 18. Jahrhundert. Mitteilungen des Vereines für Geschichte der Deutschen in Böhmen 67, 1029, Hf. 3-4, S. 114-125.

NIUBO, Marc. Auf den Spuren der Musikaliensammlung der Teynkirche. Ein Beitrag zur Musikgeschichte der Kirche St. Maria vor dem Teyn im 17. und 18. Jahrhundert. In ČERNÝ, Jaromír - KOCH, Klaus-Peter, eds. Mitteleuropäische Aspekte des Orgelbaus und der geistlichen Musik in Prag und den böhmischen Ländern: Konferenzbericht Prag, 17.-22. September 2000. Sinzig: Studio, 2002, S. 289-297.

NIUBÓ, Marc. Leopold I. a hudba císařského dvora v Praze v letech 1679-1680 [Leopold I. und die Musik des Kaiserhofes in Prag in den Jahren 1679-1680]. In Barokní Praha - Barokní Čechie 1620-1740 [Barockes Prag - Barockes Böhmen 1620-1740], Praha 2004, S. 95-131.

NIUBÓ, Marc. Vincenzo Albrici u pražských jezuitů na konci 17. století [Vincenzo Albrici bei den Prager Jesuiten am Ende des 17. Jahrhunderts], In ČEMUS, Petronilla, ed. Bohemia Jesuitica 1556-2006. V Praze: Karolinum, 2010. Bd. 1081-1094.

OULÍKOVÁ, Petra. Künstlerische Ausstattung von Altären und Kapellen der von Jesuiten betreuten Bruderschaften in Prag. In Bohemia Jesuitica 1556-2006, Praha: Karolinum, 2010, Bd. 2, S. 1217-1238.

PODLAHA, Antonín. Dějiny kolejí jesuitských v Čechách a na Moravě od r. 1654 až do jejich zrušení. Část první, Od roku 1654 do 1723. [Die Geschichte der Jesuitenkollegs in Böhmen und Mähren von 1654 bis zu ihrer Auflösung. Erster Teil, Von 1654 bis 1723]. Praha 1914.

PODLAHA, Antonín. Catalogus collectionis operum artis musicae quae bibliotheca capituli metropolitani pragensis asservantur (Editiones Archivii et Bibliothecae S.F. Metropolitani capituli pragensia XIX). Pragae: Sumptibus S.F. Metropolitani capituli prag., 1926.

POŠTOLKA, Milan. Libreta strahovské hudební sbírky / Die Libretti der Strahover Musiksammlung. Miscellanea musicologica 25-26, 1973, S. 79-149.

Prager deutsche Meister: der ersten Hälfte des 18. Jahrhunderts: Chorwerke. Theodor VEIDL, ed. Reichenberg: Ullman, 1943. Das Erbe deutscher Musik II/4.

PULKERT, Oldřich. Domus Lauretana Pragensis: Catalogus collectionis operum artis musicae. Pars 1, Catalogus. Praha: Supraphon, 1973.

RIEDEL, Friedrich W. Der Göttweiger thematische Katalog von 1830. München: Katzbichler, 1979.

Rorate coeli. Advent and Christmas in Baroque Prague [CD Audio]. Collegium Marianum, Jana Semerádová. Praha: Supraphon, 2009, SU 4002-2.

SEHNAL, Jiří. Pobělohorská doba (1620-1740) [Die Zeit nach dem Weißen Berg]. In ČERNÝ, Jaromír aj. Hudba v českých dějinách: od středověku do nové doby. 2. Ed. Praha: Supraphon, 1989, S. 147-215.

SLAVICKÝ, Tomáš. Hudební život klášterů Nového Města pražského v letech 1680-1780 [Das Musikleben der Klöster der Prager Neustadt 1680-1780]. In Locus pietatis et vitae. Praha: UK Scriptorium, 2008, S. 481-506.

ŠTEFAN, Jiří. Ecclesia metropolitana Pragensis catalogus collectionis operum artis musicae. 2 Bd. Praha: Supraphon, 1983-1985.

ŠTEFANCOVÁ, Dagmar, KABELKOVÁ, Markéta, PAULOVÁ, Eva. Hudební sbírka Ondřeje Horníka. I. díl, Sbírka hudebnin, knihovna a výtvarné dokumenty [Ondřej Horníks Musiksamm- 
lung. I. Teil, Musikaliensammlung, Bibliothek und Kunstdokumente]. Praha: Národní muzeum, 2012. Editio Monographica Musei Nationalis Pragae; 14/1.

STOCKIGT, Janice B. The Vespers psalms of Jan Dismas Zelenka (1679-1745) in the liturgy and life of the Dresden Catholic court church. Melbourne: University of Melbourne, 1994.

TANK, Ulrich. Studien zur Esterházyschen Hofmusik von etwa 1620 bis 1790 . Regensburg: G. Bosse, 1981.

TROLDA, Emilián. Z české barokní hudby [Aus der böhmischen Barockmusik]. Cyril 63, 1937, č. 9-10, s. 105-107.

VEVERKA, Karel. Hudební mecenát hraběte Jana Huberta Hartiga u pražských Křižovníků s červenou hvězdou ve světle řádového listinného archivu [Das Musikmäzenatentum des Grafen Jan Hubert Hartigs bei der Prager Kreuzherren mit rotem Stern im Licht des Ordensarchivs]. Hudební věda 50, 2014, im Druck.

VLČEK, Pavel u.a., Umělecké památky Prahy. Malá Strana [Prager Kunstdenkmäler, Kleinseite]. Praha 1999.

VOLEK, Tomislav. Die Bedeutung Prags für Zelenkas Leben und Schaffen, In Zelenka-Studien I (Musik des Ostens 14). Kassel: Bärenreiter, 1993. S. 17-40.

VOLEK, Tomislav. Emilián Trolda a edice pražských mistrů v Das Erbe Deutscher Musik II/4 [Emilián Trolda und die Edition Prager Meister in EdM]. Hudební věda 37, 2000, č. 3-4, S. 239-241.

Zaniklé chrámy: živá hudba = Extinct churches: living music. Praha: Národní muzeum, 2007.

ZELENKA, Jan Dismas. Missa Omnium Sanctorum a-moll ZWV 21, Litaniae Lauretanae „Salus infirmorum" "F-Dur ZWV 152. HORN, Wolfgang, KOHLHASE, Thomas, eds. Wiesbaden: Breitkopf \& Härtel, 1989. Das Erbe deutscher Musik 101.

Zelenka-Studien I (Musik des Ostens 14). Kassel: Bärenreiter, 1993.

Zelenka-Studien 2: Referate und Materialien der 2. Internationalen Fachkonferenz Jan Dismas Zelenka (Dresden und Prag 1995). St. Augustin: Academia Verlag, 1997.

ZOBELEY, Fritz. Die Musikalien der Grafen von Schönborn-Wiesentheid: Thematisch-bibliographischer Katalog, I. Teil: Das Repertoire des Grafen Rugolf Franz Erwein von Schönborn (1677-1754). Bd. 2: Handschriften. DANGEL-HOFMANN, Frohmut (ed.), Tutzing 1982. 
